\title{
Record Fast-Cycling Accelerator Magnet Based on High-Temperature Superconductor
}

Henryk Piekarz, Steven Hays, Jamie Blowers, Bradley Claypool and Vladimir Shiltsev

Fermilab, Batavia, III 60510, USA

\section{Abstract-}

We report on the prototype high-temperature superconductor (HTS) based accelerator magnet capable to operate at $12 \mathrm{~T} / \mathrm{s}$ B-field ramping rate with a very low cryogenic power loss thus indicating a possibility of its application for the accelerators requiring high repetition rate and high average beam power. Further details of design, construction and test arrangement of this prototype rapid-cycling HTS based magnet are presented in [1]. The measured cryogenic power loss limit in the magnet power test is discussed in terms of the feasibility of application of such a magnet for construction of a dual proton beam booster accelerator.

\section{Motivation}

Next generation of particle physics facilities such as muon colliders [2], future circular colliders (FCC) [3] and high beam intensity proton synchrotrons for neutrino research $[4,5,6,7]$ require much faster cycles of beam acceleration than available at present while minimizing accelerator operation power needed to compensate for the magnetization losses in the conductor and magnetic core. Use of the superconductors strongly reduces the size of both the power cable and the magnetic core leading in turn to a strong reduction of the accelerator construction cost and the required operation power.

\section{HTS Rapid-Cycling Accelerator Magnet Design}

\section{Magnetic core design}

High current density of superconductor reduces significantly cross-section of magnet power cable which in turn reduces cross-section of magnetic core. As a result the power losses induced by fast ramping magnetic field are strongly reduced in both the cable and the core.

Superconducting power cable can be arranged as a narrow slab which when combined with its optimized position within cable core space leads to strong minimization of cable exposure to core descending magnetic field

Magnetic core design for $1 \mathrm{~T}$ field in the $100 \mathrm{~mm}(\mathrm{H}) \times 40 \mathrm{~mm}(\mathrm{~V})$ beam gap. HTS conductor cross-section for $36 \mathrm{kA}$ current is $15 \mathrm{~mm}^{2}$ but cable slab size is $8 \mathrm{~cm}^{2}$ to accommodate cable cryogenic support. Less than $5 \%$ of B-field in the beam gap crosses the cable space.

\section{Magnet design criteria:}

(i) Single conductor coil energizes 2 beam gaps allowing simultaneous acceleration of 2 beams

(ii) Beam gaps are aligned in vertical plane so beam losses and particle decays are mitted into space away from the cable.

(III) Three part core assembly allows for easy installation of conductor coil.

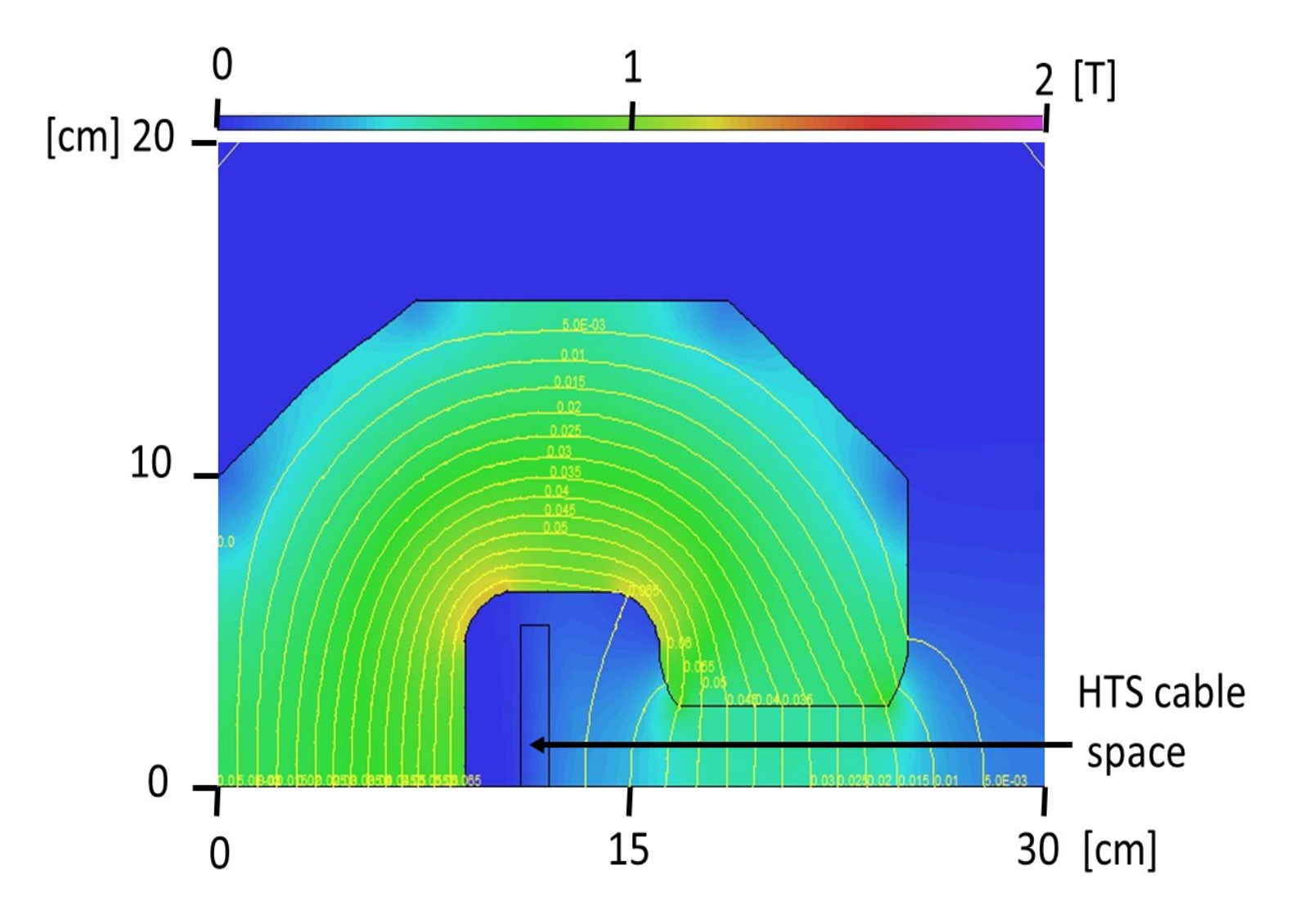

\section{HTS power cable}

HTS superconductor can operate within wide temperature margin. With number of strands allowing to carry transport current e.g. up to $35 \mathrm{~K}$ the operational temperature of $4.5 \mathrm{~K}$ allows for $30 \mathrm{~K}$ safety margin facilitating operation of quench detection and protection systems. In order to minimize magnet current a 3-turn conductor coil is used.

The $2 \mathrm{~mm}$ wide, $0.1 \mathrm{~mm}$ thick HTS strands are helically wound at $10 \mathrm{~cm}$ pitch on the surface of $316 \mathrm{LN}$ pipe Of $8 \mathrm{~mm}$ OD, $0.5 \mathrm{~mm}$ wall. A single layer of $0.1 \mathrm{~mm}$ thick, $12.5 \mathrm{~mm}$ wide copper tape is helically wound over strands to secure their firm attachment to the cooling helium conduit pipe.

Up to 12 HTS strands can be placed on each helium pipe allowing for $36 \mathrm{kA}$ magnet transport current which would generate $0.7 \mathrm{~T}$ in a $50 \mathrm{~mm}$ beam gap.

For the test magnet there are only 2 strands attached to each He conduit pipe. There are 12 strands in the test magnet power cable of $24 \mathrm{~m}$ total length of which $12 \mathrm{~m}$ is inside magnet core.
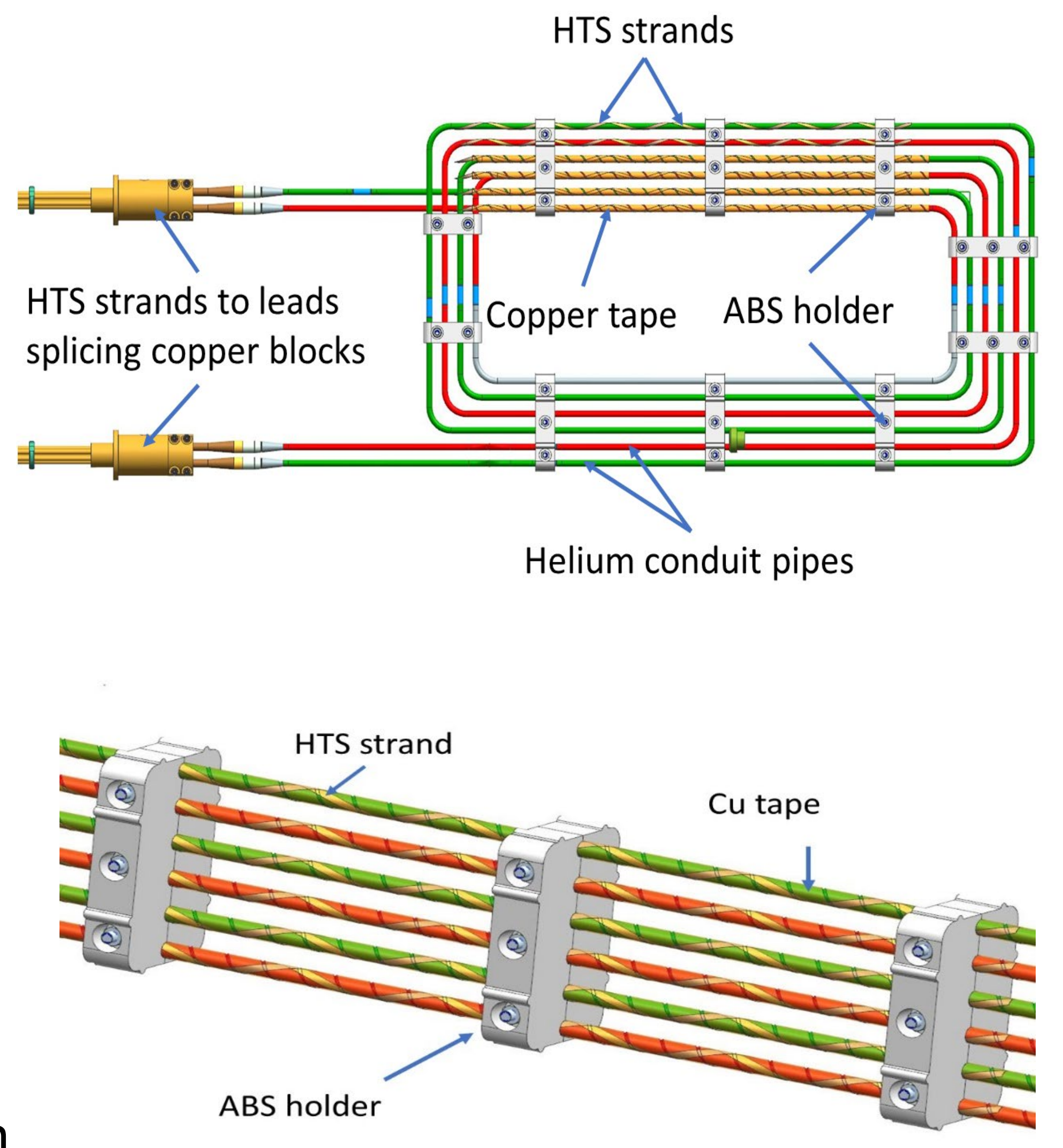

\section{HTS Magnet Test Arrangement}

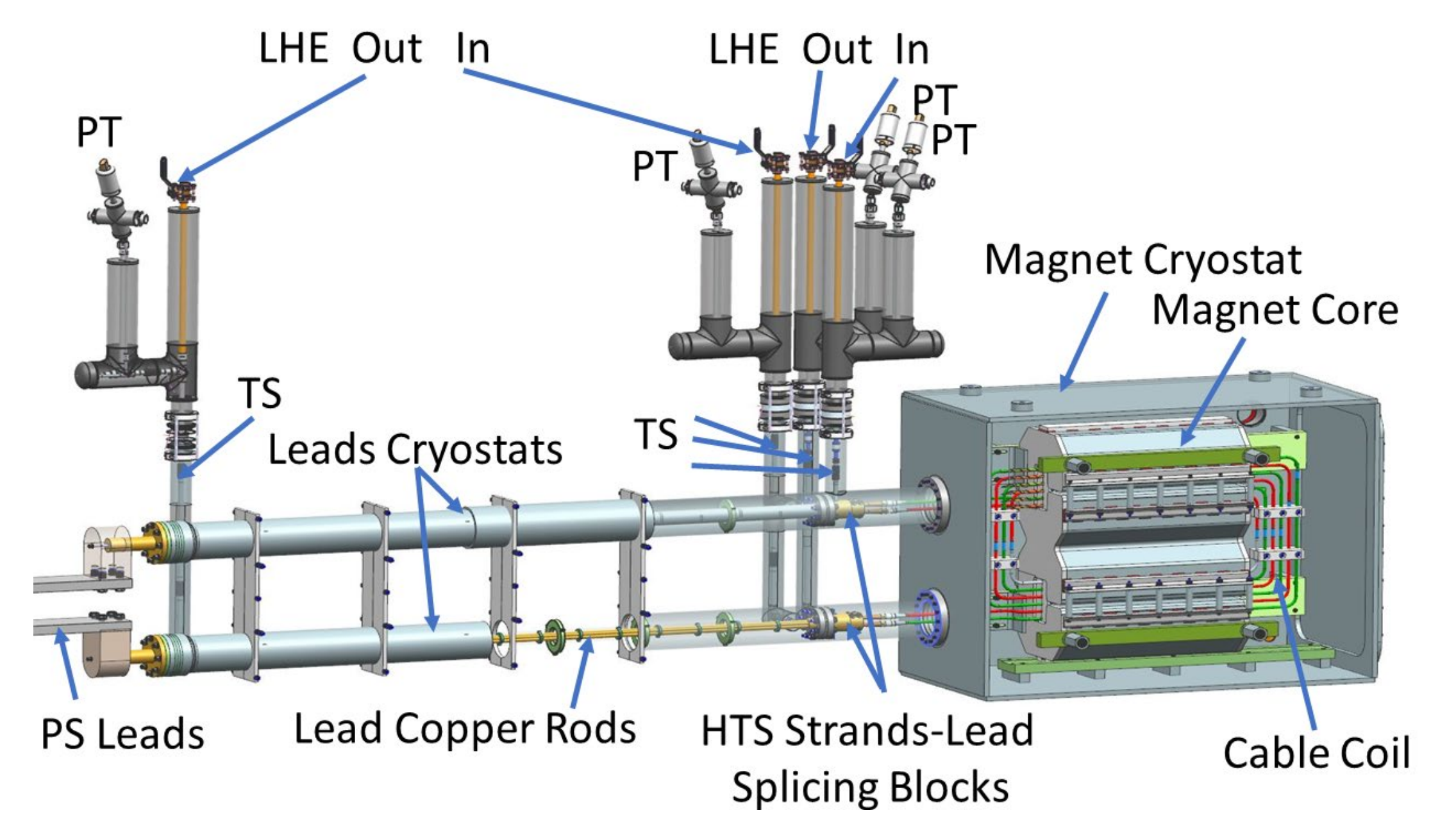

The magnet HTS conductor coil and conventional current leads are cooled using separate liquid helium flows. Pressure and temperature sensors are placed in the inlets and outlets of helium circuits. Liquid helium from magnet coil and current leads exits into $3.6 \mathrm{~kW}$ heaters which warm liquid helium to room temperature before passing it into flow meters and then returning to cryogenic plant. The difference in $\mathrm{He}$ outlet and inlet temperature together with measured flow rate and pressure is used to determine cryogenic power loss through the change of helium enthalpy which equals the change of energy when combined with helium flow rate.

\begin{tabular}{ll} 
HTS Test Magnet Properties & \\
\hline Cable critical current @ 6.5 K & $6 \mathrm{kA}$ \\
Cable critical current @ 30 K & $2 \mathrm{kA}$ \\
Magnet critical current @30 K & $6 \mathrm{kA}$ \\
Magnet applied current & $1.9 \mathrm{kA}$ \\
Maximum B-field & $0.23 \mathrm{~T}$ \\
Magnet resistance @ 6.5 K & $340 \Omega$ \\
Magnet inductance & $96 \mu \mathrm{H}$ \\
Leads inductance & $4 \mu \mathrm{H}$
\end{tabular}

Magnet Power Test Results

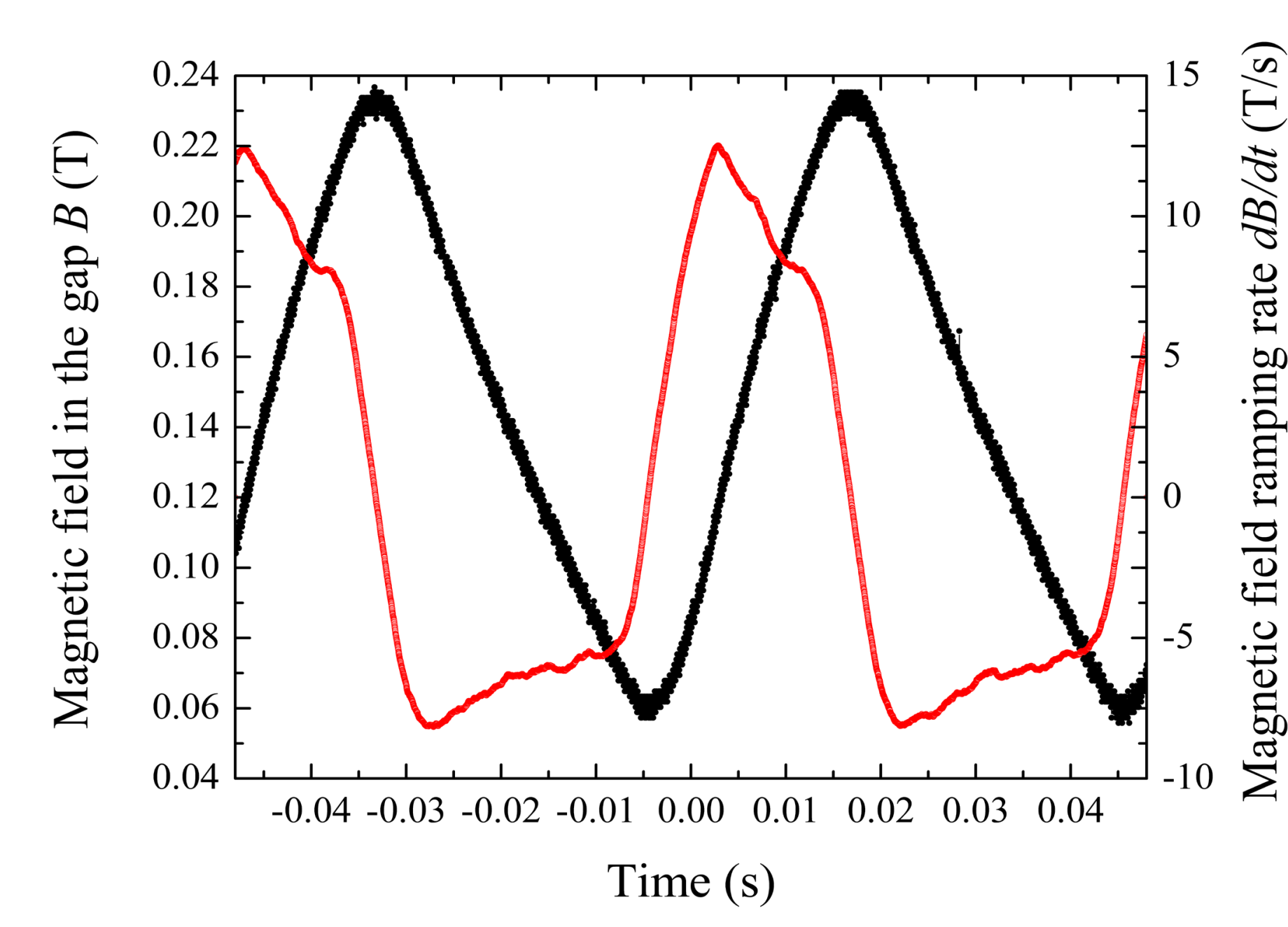

Cryogenic Power Projection for $8 \mathrm{GeV}$ Dual Beam Booster

Magnet current wave-form composed of two AC current pulses as shown in figure below eliminates the need for the high-current DC offset.

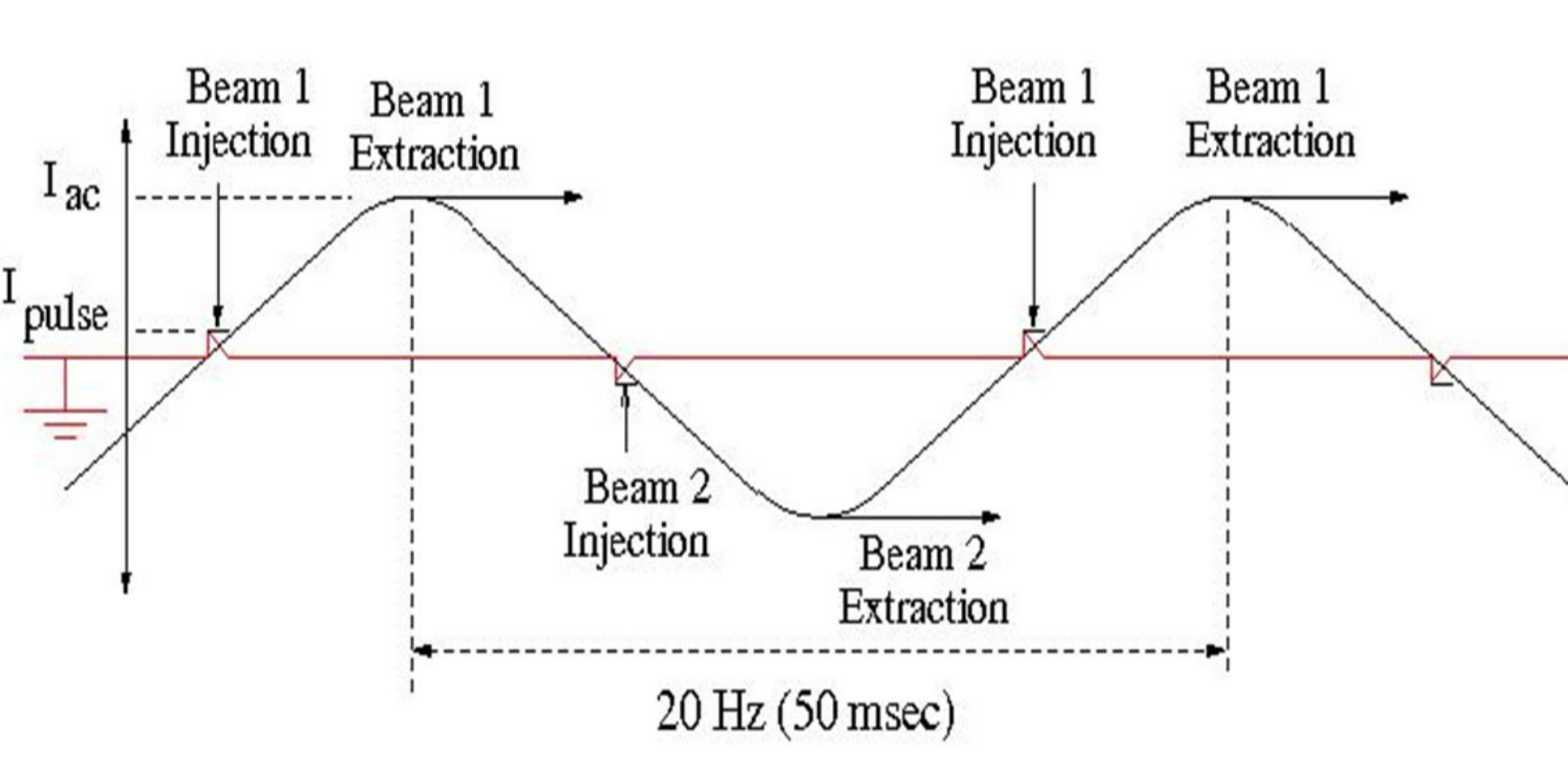

References

[1] H. Piekarz etr al., Nucl. Instr. \& Methods, Vol 943, 2019 [2] D. Neuffer and V. Shiltsev JINST 13, T1003 (2018) 3] M. Benedikt et al. Report CERN-ACC-2018-0057

[4] A. Milanese, H. Piekarz and L. Rossi, IPAC-5 (2014) [5] H. Piekarz, IPAC-6, e-print arXiV:1205.1527 (2015) [6] E. Prebys et al., IPAC-7, 1010-1012 (2016) 77] S. Nagaitsev and V. Lebedev, arXiV: 1812.10930 8] H. Piekarz, S. Hays, J. Blowers, V. Shiltsev, IEEE, Trans.. Appl. Superconductivity, 22,5800105 (2012)

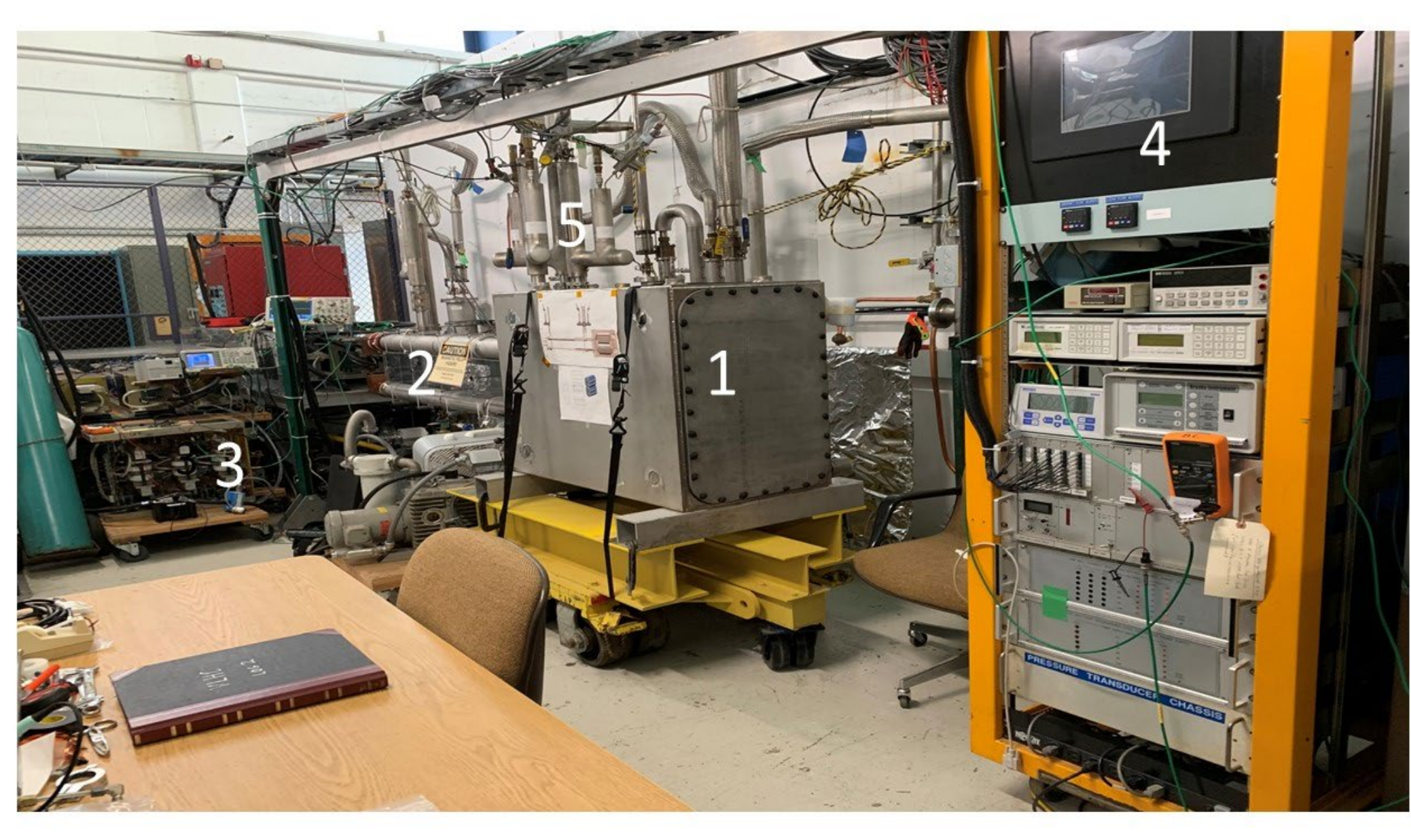

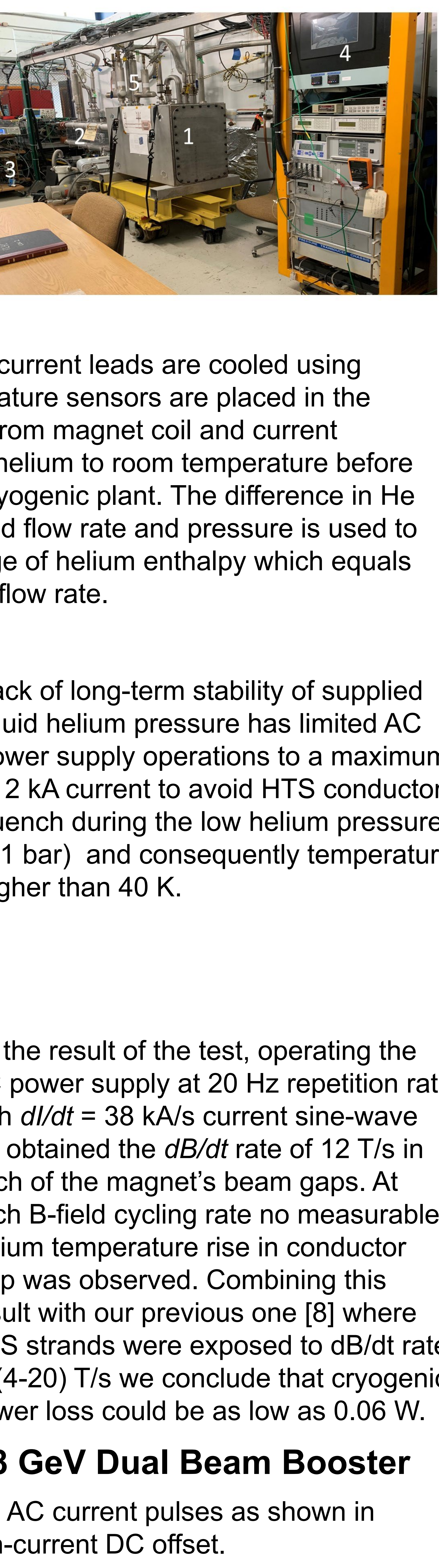

$8 \mathrm{GeV}$ Dual Proton Beam Booster

$\begin{array}{lcc}\text { Circumference } & {[\mathrm{m}]} & 474 \\ \text { Magnet string } & {[\mathrm{m}]} & 380 \\ \text { Beam gaps } & {[\mathrm{mm} \times \mathrm{mm}]} & 50 \times 100 \\ \text { B-field } & {[\mathrm{T}]} & +/-0.7 \\ \text { Magnet current } & {[\mathrm{kA}]} & 36 \\ \text { Repetition rate } & {[\mathrm{Hz}\}} & 20 \\ \text { dB/dt } & {[\mathrm{T} / \mathrm{s}]} & 36 \\ \text { Cryogenic power } & {[\mathrm{kW}]} & 1.9\end{array}$

